\title{
Características das Partes do Corpo Não-integrantes da Carcaça de Novilhos Jovens e Superjovens de Diferentes Grupos Genéticos ${ }^{1}$
}

\author{
Paulo Santana Pacheco ${ }^{2}$, João Restle ${ }^{3}$, José Henrique Souza da Silva4, Miguelangelo Ziegler \\ Arboitte $^{5}$, Dari Celestino Alves Filho ${ }^{6}$, Aline Kellermann de Freitas ${ }^{7}$, Joilmaro Rodrigo Pereira Rosa ${ }^{8}$, \\ João Teodoro Pádua ${ }^{9}$
}

RESUMO - Objetivou-se, com este estudo, avaliar os componentes do corpo não-integrantes da carcaça de novilhos jovens (abatidos aos 22,8 meses de idade) e superjovens (abatidos aos 15,2 meses de idade) dos grupos genéticos 5/8 Charolês (CH) 3/8 Nelore (NE) e 5/8NE 3/8CH e a relação entre as variáveis estudadas. Os animais foram terminados em confinamento até atingirem $430 \mathrm{~kg}$. A dieta alimentar continha relação volumoso:concentrado de 60:40 (base na matéria seca), com 10,25\% de proteína bruta e 3,18 Mcal de energia digestível/ kg de matéria seca. O delineamento experimental foi o inteiramente casualizado, com seis repetições, em arranjo fatorial 2 x 2 (duas categorias $\mathrm{x}$ dois grupos genéticos). Houve similaridade para peso de abate (PAB) e peso de corpo vazio (PCV) entre categorias e grupos genéticos. Quando os componentes foram expressos em valores absolutos e ajustados para PCV e PAB, novilhos jovens apresentaram maiores pesos de coração, fígado, omaso vazio e total de órgãos vitais, e novilhos superjovens apresentaram maiores pesos de couro, gordura renal, gordura de toalete e total de gorduras internas. Enquanto novilhos 5/8CH 3/8NE apresentaram maiores pesos de fígado, gordura renal, total de órgãos vitais e sangue, aos novilhos 5/8NE 3/8CH corresponderam os maiores pesos de couro e total de componentes externos. Quando ajustado para PCV, novilhos jovens apresentaram maiores pesos dos componentes pulmão, rúmen+retículo vazio e total de trato digestivo vazio, ao passo que novilhos 5/8CH 3/8NE apresentaram maior peso total de trato digestivo vazio. Cada kg de gordura intermuscular depositada na carcaça representou aumento de 0,006 pontos no estado corporal ao abate, 0,113 mm na espessura de gordura subcutânea, 0,253 kg na gordura ruminal+visceral, $0,089 \mathrm{~kg}$ na gordura renal, 0,076 kg na gordura de toalete e 0,040 kg na gordura inguinal. Houve relação positiva entre exigência de energia líquida de mantença e peso dos componentes dos órgãos vitais.

Palavras-chave: couro, cruzamento, ganho compensatório, gordura interna, peso de corpo vazio, rúmen-retículo

\section{Characteristics of Non Integrate Body Components of Carcass of Steers and Young Steers of Different Genetic Groups}

\begin{abstract}
The objective of this trial was to evaluate the components of non integrate body components of carcass of two categories, steers (slaughtered at 22.8 months old) and young steers (slaughtered at 15.2 months old), from two genetic groups, $5 / 8 \mathrm{Charolais}$ (CH) 3/8 Nellore (NE) and 5/8NE 3/8CH, and to evaluate the relationship among the variables studied. The animals were fedlot finished until reaching $430 \mathrm{~kg}$. The diet, roughage:concentrate ratio of 60:40 (dry matter basis), contained 10.25\% crude protein and 3.18 Mcal of digestible energy/kg of dry matter. The experiment was analyzed as a complete randomized design with six replicates, according to a 2 x 2 (two categories x two genetic groups) factorial scheme. Slaughter weight (SW) and empty body weight (EBW) were similar between categories and between genetic groups. When the components were expressed as absolute values and adjusted for EBW and SW, steers showed higher heart, liver, empty omasum and total vital organs weights, and young steers showed higher rawhide, kidney fat, trim fat and total internal fats weights. While 5/8CH 3/8NE showed higher liver, kidney fat, total vital organs and blood weights, and 5/8NE 3/8CH higher rawhide and total external components weights. When adjusted for EBW, steers showed higher weights of components lung, empty rumen+reticulum and total empty digestible tract, while 5/8CH 3/8NE showed higher total empty digestible tract weight. Each $\mathrm{kg}$ of intermuscular fat deposited in the carcass represented increase of 0.006 points in slaughter body condition score, $0.113 \mathrm{~mm}$ in subcutaneous fat thickness, $0.253 \mathrm{~kg}$ in ruminal+visceral fat, $0.089 \mathrm{~kg}$ in kidney fat, $0.076 \mathrm{~kg}$ in trim fat and $0.040 \mathrm{~kg}$ in inguinal fat. Positive relation was verified among requirement of net energy for maintenance and weight of vital organs components.
\end{abstract}

Key Words: compensatory gain, crossbreeding, empty body weight, rawhide, rumen-reticulum

\footnotetext{
1 Parte da Dissertação de Mestrado do primeiro autor - PPGZ/UFSM.

2 Zootecnista, MSc. Doutorando do PPGCA-UFG. E.mail: pspacheco@pop.com.br

3 Engenheiro Agrônomo, PhD. Pesquisador Visitante/CNPq-DPA/UFG. E,mail: jorestle@terra.com.br

4 Engenheiro Agrônomo, PhD. Professor Adjunto do Departamento de Zootecnia da UFSM.

5 Zootecnista, MSc. Professor do Departamento de Zootecnia da UFSM.

${ }^{6}$ Engenheiro Agrônomo, MSc. Professor Assistente do Departamento de Zootecnia da UFSM.

7 Zootecnista, aluna de Mestrado do PPGCA - UFV. Bolsista CNPq.

8 Engenheiro Agrônomo, MSc. Doutorando do PPG Zootecnia - UFRGS.

${ }^{9}$ Zootecnista, Dr. Professor Adjunto do Departamento de Produção Animal - EV/UFG.
} 


\section{Introdução}

De maneira geral, a comercialização de bovinos de corte entre produtor e frigorífico no Brasil é feita com base no peso de carcaça quente ou, como na região Sul, pelo peso vivo do animal anterior ao embarque para o frigorífico ou pelo peso de carcaça fria.

Para o frigorífico, a fonte de receita com o abate de bovinos de corte vai além da comercialização da carcaça fria em cortes comerciais inteiros ou desossados. Cada vez mais os componentes não-integrantes da carcaça, também denominados componentes de corpo vazio, estão sendo utilizados para geração de receita, seja pela venda no atacado, como o caso das gorduras, dos ossos limpos, do fígado, coração, entre outros, seja pela agregação de valor com a fabricação de embutidos e afins.

Um subproduto do abate de bovinos muito valorizado pelos frigoríficos é o couro, que pode ser comercializado antes ou após a salga. Segundo dados do ANUALPEC (2003), nos últimos cinco anos, a quantidade e o valor pago por kg de couro comercializado tanto no atacado como pelas exportações é crescente, uma vez que este subproduto desempenha importante papel em outros segmentos da economia, destacando-se a indústria de calçados e vestuário.

Quanto aos demais componentes do corpo vazio, outra implicação prática estaria relacionada ao rendimento de carcaça e às exigências energéticas dos animais, sobretudo de energia líquida de mantença. Estudos apontam para existência de relação negativa entre peso dos componentes externos e trato digestivo com o rendimento de carcaça (Galvão et al., 1991; Restle et al., 2001; Vaz et al., 2001; Santos et al., 2003 a). Outros demonstram que animais com maiores pesos de órgãos vitais, principalmente fígado, e maior acúmulo de gordura interna são energeticamente mais exigentes (Jones et al., 1985; Owens et al., 1993; Ferrel \& Jenkins, 1998). Além disso, a avaliação dos componentes do corpo vazio em bovinos de corte pode ser valiosa para o entendimento de características relacionadas ao desempenho e à carcaça dos animais.

Neste experimento, objetivou-se avaliar as características das partes do corpo não-integrantes da carcaça de novilhos jovens e superjovens dos grupos genéticos 5/8Charolês 5/8Nelore e 5/8Nelore $3 / 8$ Charolês e a relação entre as variáveis estudadas.

\section{Material e Métodos}

O experimento foi conduzido no Setor de Bovinocultura de Corte do Departamento de Zootecnia da Universidade Federal de Santa Maria, no município de Santa Maria - RS, localizado na região fisiográfica Depressão Central, a 153 m de altitude, que, segundo classificação de Köppen, apresenta clima subtropical úmido (cfa) (Moreno, 1961).

Foram utilizados 24 novilhos castrados, com média de sete meses de idade, provenientes do mesmo rebanho, dos grupos genéticos 5/8Charolês ( $\mathrm{CH}$ ) 3/8Nelore $(\mathrm{NE})$ e $5 / 8 \mathrm{NE} 3 / 8 \mathrm{CH}$, pertencentes às categorias jovem, caracterizada por animais abatidos com idade entre 20-24 meses (abatidos com idade média de 22,8 meses de idade); e superjovem, caracterizada por animais abatidos com idade entre 12-16 meses (abatidos com média de 15,2 meses de idade).

Durante o período de terminação em confinamento, os animais foram alimentados à vontade, duas vezes ao dia, de manhã (8 h) e à tarde (17 h). A dieta foi calculada segundo o NRC (1996), objetivando-se um ganho de peso médio diário de 1,6 kg/animal e estimando-se um consumo de $2,5 \mathrm{~kg}$ de matéria seca (MS)/100 kg peso vivo (PV). Para todos os animais, foi utilizada relação volumoso:concentrado de 60:40 (base na MS), com dieta contendo 10,25\% de proteína bruta e 3,18 Mcal de energia digestível/kg de MS. Os ingredientes e suas composições percentuais na dieta, com base na matéria seca, foram: silagem de milho $(60,00 \%)$, farelo de trigo (28,24\%), sorgo grão (10,07\%), uréia (45-00-00) (0,17\%), calcário calcítico $(1,02 \%)$, sal comum $(\mathrm{NaCl})(0,48 \%)$ e ionóforo (Rumensin $\left.{ }^{\circledR}\right)(0,0128 \%)$.

Ao atingirem o peso de abate preconizado $(430 \mathrm{~kg})$, os animais foram submetidos a jejum de sólidos de 14 horas, anterior à pesagem final de abate. Em seguida, foram transportados a um frigorífico comercial a $25 \mathrm{~km}$ do local do experimento e abatidos por concussão cerebral e secção da veia jugular, segundo o fluxo normal do estabelecimento. O período médio de alimentação em confinamento foi de 35 dias para os novilhos jovens e 143 dias para os superjovens.

Durante o abate, todas as partes do corpo do animal foram separadas e pesadas individualmente, e consistiram de: conjunto de componentes externos cabeça, patas, orelhas, chifres (quando presentes), vassoura da cauda e couro; conjunto de órgãos vitais 
- pulmão, fígado, rins, coração e baço; conjunto de gorduras internas: gordura de toalete, gordura inguinal, gordura renal e gordura ruminal+visceral; conjunto do trato digestivo vazio - rúmen-retículo, omaso, abomaso, intestino grosso e intestino delgado vazios; e sangue.

Antes de serem encaminhadas à câmara de resfriamento, as duas meia-carcaças foram identificadas e pesadas, obtendo-se o peso de carcaça quente. O peso de corpo vazio (PCV) foi obtido pelo somatório do peso de carcaça quente, sangue e de todos os componentes agrupados conforme citado anteriormente.

O delineamento experimental adotado foi o inteiramente casualizado, em arranjo fatorial 2 x 2 (duas categorias $\mathrm{x}$ dois grupos genéticos). Cada tratamento foi composto por seis repetições, em que cada animal constituiu uma unidade experimental. Foram realizadas as análises de variância, aplicando-se o teste $\mathrm{F}$ e,quando houve interação significativa a 5\%, efetuouse o teste Tukey e as análises de correlação de Pearson e de regressão múltipla, utilizando-se o programa estatístico SAS (1997). O modelo matemático utilizado foi:

$$
\Upsilon_{i j k}=\mathrm{m}+\mathrm{GG}_{i}+\mathrm{C}_{j}+\left(\mathrm{GG}^{*} \mathrm{C}\right)_{i j}+\varepsilon_{i j k},
$$

em que: $\Upsilon_{i j k}=$ variáveis dependentes; $\mathrm{m}$ = média geral de todas as observações; $\mathrm{GG}_{i}=$ efeito do grupo genético de ordem " $i$ ", sendo $1=5 / 8$ Charolês $3 / 8$ Nelore e 2 = 5/8Nelore 3/8Charolês; $C_{j}=$ efeito da categoria de ordem “j”, sendo 1 = jovem e 2 = superjovem; $\left(G G^{*} C\right)_{i j}$
= interação do i-ésimo grupo genético e da j-ésima categoria; $\varepsilon_{i j k}=$ erro aleatório residual, $\operatorname{NID}\left(0, \sigma^{2}\right)$.

Os dados foram testados quanto à normalidade, por meio do teste de Shapiro-Wilk (SAS, 1997), efetuando-se, quando necessário, a transformação da raiz quadrada dos dados dos parâmetros.

\section{Resultados e Discussão}

Na Tabela 1, estão apresentados os valores médios referentes aos pesos de abate e de corpo vazio, de acordo com a categoria e o grupo genético. Verificouse que o peso de abate apresentou similaridade para os diferentes efeitos estudados, o que era esperado, uma vez que foi previamente estipulado. Semelhança entre categorias e grupos genéticos também foi verificada para peso de corpo vazio, em decorrência da similaridade no peso de carcaça quente (Pacheco et al., 2005b) e das variações nos demais componentes do corpo vazio dos animais.

As médias referentes aos pesos dos componentes externos, expressos em valores absolutos e ajustados para peso de corpo vazio e peso de abate, de acordo com a categoria e o grupo genético, estão apresentadas na Tabela 2.

O peso de couro apresentou diferença entre categorias e grupos genéticos. Entre as categorias, foi superior nos novilhos superjovens, o que não era esperado, uma vez que os animais apresentaram similaridade nos pesos de abate e de corpo vazio (Tabela 1). Isto pode estar associado ao nível nutricional a que os

Tabela 1 - Médias para peso de abate e peso de corpo vazio, de acordo com a categoria e grupo genético Table 1 - Means for slaughter weight and empty body weight, according to category and genetic group

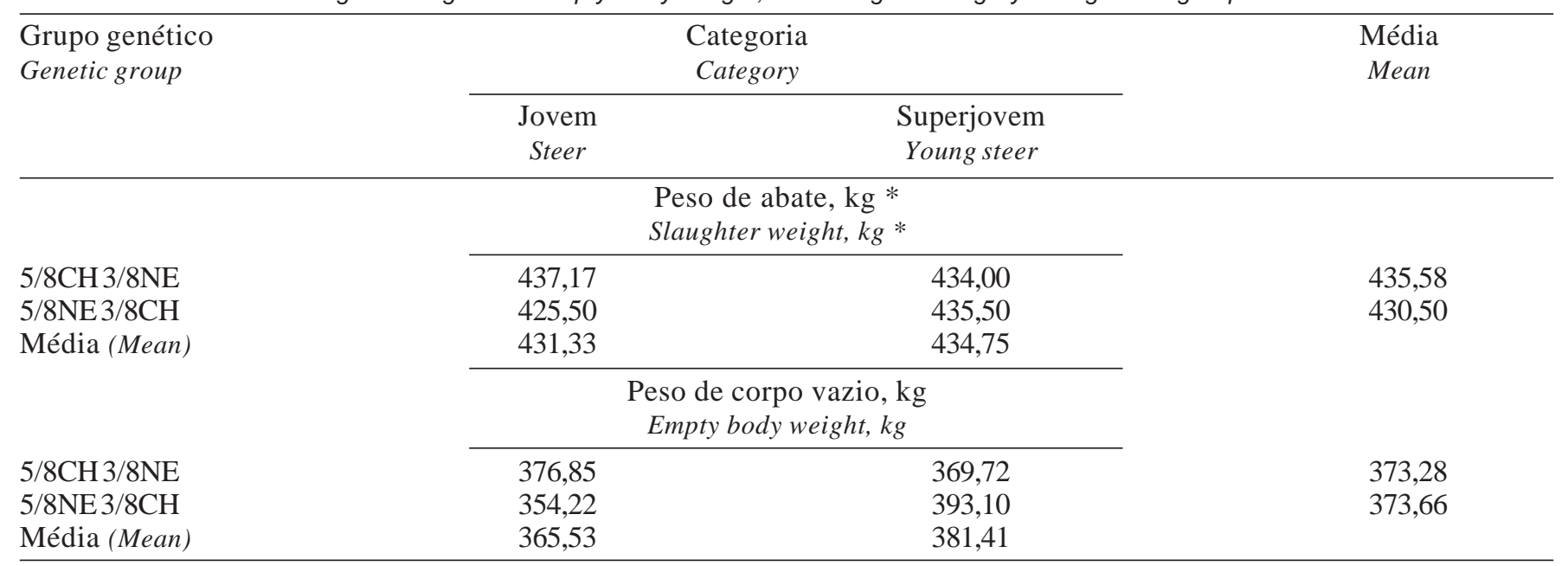

* Obtido de Pacheco et al. (2005b) (Obtained from Pacheco et al., 2005b data).

$P>0,05(P>.05)$. 
Tabela 2 - Médias para peso absoluto, em relação aos pesos de corpo vazio (PCV) e peso de abate (PAB) dos diferentes componentes externos

Table 2 - Means for absolute weights, in relation to empty body weight (PCV) and slaughter weight (PAB) of different external components

\begin{tabular}{|c|c|c|c|c|c|c|c|c|c|}
\hline \multirow[t]{2}{*}{$\begin{array}{l}\text { Grupo genético } \\
\text { Genetic group }\end{array}$} & \multicolumn{2}{|c|}{$\begin{array}{l}\text { Categoria } \\
\text { Category }\end{array}$} & \multirow[t]{2}{*}{$\begin{array}{l}\text { Média } \\
\text { Mean }\end{array}$} & \multicolumn{2}{|c|}{$\begin{array}{c}\text { Categoria } \\
\text { Category }\end{array}$} & \multirow[t]{2}{*}{$\begin{array}{l}\text { Média } \\
\text { Mean }\end{array}$} & \multicolumn{2}{|c|}{$\begin{array}{l}\text { Categoria } \\
\text { Category }\end{array}$} & \multirow[t]{2}{*}{$\begin{array}{l}\text { Média } \\
\text { Mean }\end{array}$} \\
\hline & $\begin{array}{c}\text { Jovem } \\
\text { Steer }\end{array}$ & $\begin{array}{l}\text { Superjovem } \\
\text { Young steer }\end{array}$ & & $\begin{array}{l}\text { Jovem } \\
\text { Steer }\end{array}$ & $\begin{array}{l}\text { Superjovem } \\
\text { Young steer }\end{array}$ & & $\begin{array}{l}\text { Jovem } \\
\text { Steer }\end{array}$ & $\begin{array}{l}\text { Superjovem } \\
\text { Young steer }\end{array}$ & \\
\hline & \multicolumn{2}{|c|}{ Chifres (Horns), kg } & & \multicolumn{2}{|c|}{ Chifres (Horns), \% PCV } & & \multicolumn{2}{|c|}{ Chifres (Horns), \% PAB } & \\
\hline 5/8CH3/8NE & 0,05 & 0,03 & 0,04 & 0,01 & 0,01 & 0,01 & 0,01 & 0,01 & 0,01 \\
\hline 5/8NE 3/8CH & 0,11 & 0,03 & 0,07 & 0,04 & 0,01 & 0,02 & 0,03 & 0,01 & 0,02 \\
\hline \multirow[t]{2}{*}{ Média (Mean) } & 0,08 & 0,03 & & 0,02 & 0,01 & & 0,02 & 0,01 & \\
\hline & \multicolumn{2}{|c|}{ Orelhas (Ears), kg } & & \multicolumn{2}{|c|}{ Orelhas (Ears), \% PCV } & & \multicolumn{2}{|c|}{ Orelhas (Ears), \% PAB } & \\
\hline 5/8CH3/8NE & 0,55 & 0,53 & 0,54 & $0,15 b$ & $0,14 \mathrm{~b}$ & 0,14 & 0,13 & 0,12 & $0,12 b$ \\
\hline 5/8NE3/8CH & 0,61 & 0,56 & 0,58 & $0,17 \mathrm{a}$ & $0,14 b$ & 0,16 & 0,14 & 0,13 & $0,14 \mathrm{a}$ \\
\hline \multirow[t]{2}{*}{ Média (Mean) } & 0,58 & 0,54 & & 0,16 & 0,14 & & $0,13 \mathrm{~A}$ & $0,12 \mathrm{~B}$ & \\
\hline & \multicolumn{2}{|c|}{ Cabeça (Head), kg } & & \multicolumn{2}{|c|}{ Cabeça (Head), \% PCV } & & \multicolumn{2}{|c|}{ Cabeça (Head), \% PAB } & \\
\hline 5/8CH3/8NE & 13,93 & 13,78 & 13,85 & $3,70 \mathrm{~b}$ & $3,73 b$ & 3,72 & $3,19 \mathrm{ab}$ & $3,18 \mathrm{ab}$ & 3,18 \\
\hline 5/8NE3/8CH & 14,42 & 13,08 & 13,75 & $4,08 \mathrm{a}$ & $3,33 c$ & 3,71 & $3,39 a$ & $3,01 \mathrm{~b}$ & 3,20 \\
\hline \multirow[t]{2}{*}{ Média (Mean) } & 14,17 & 13,43 & & 3,89 & 3,53 & & 3,29 & 3,10 & \\
\hline & \multicolumn{2}{|c|}{ Patas (Feet), kg } & & \multicolumn{2}{|c|}{ Patas (Feet), \% PCV } & & \multicolumn{2}{|c|}{ Patas (Feet), \% PAB } & \\
\hline 5/8CH3/8NE & 8,09 & 7,53 & 7,81 & 2,15 & 2,03 & 2,09 & $1,85 a b$ & $1,73 \mathrm{~b}$ & 1,79 \\
\hline 5/8NE 3/8CH & 7,68 & 8,26 & 7,97 & 2,16 & 2,10 & 2,13 & $1,80 \mathrm{ab}$ & $1,90 \mathrm{a}$ & 1,85 \\
\hline \multirow[t]{2}{*}{ Média (Mean) } & 7,88 & 7,89 & & 2,16 & 2,07 & & 1,83 & 1,81 & \\
\hline & \multicolumn{2}{|c|}{ Vass. cauda (Tail broom), kg } & & \multicolumn{2}{|c|}{$\begin{array}{c}\text { Vass. cauda (Tail broom), } \\
\text { \%PCV } \\
\end{array}$} & & \multicolumn{2}{|c|}{$\begin{array}{c}\text { Vass. cauda (Tail broom), } \\
\% \text { PAB } \\
\end{array}$} & \\
\hline 5/8CH3/8NE & 0,25 & 0,24 & 0,25 & 0,07 & 0,06 & 0,07 & 0,06 & 0,06 & 0,06 \\
\hline 5/8NE $3 / 8 \mathrm{CH}$ & 0,26 & 0,27 & 0,27 & 0,08 & 0,07 & 0,07 & 0,06 & 0,06 & 0,06 \\
\hline \multirow[t]{2}{*}{ Média (Mean) } & 0,26 & 0,26 & & 0,07 & 0,07 & & 0,06 & 0,06 & \\
\hline & \multicolumn{2}{|c|}{ Couro (Rawhide), kg } & & \multicolumn{2}{|c|}{$\begin{array}{c}\text { Couro (Rawhide), } \\
\text { \% PCV }\end{array}$} & & \multicolumn{2}{|c|}{$\begin{array}{c}\text { Couro (Rawhide), } \\
\text { \% PAB }\end{array}$} & \\
\hline 5/8CH3/8NE & 34,05 & 36,55 & $35,30 \mathrm{~b}$ & 8,99 & 9,87 & $9,43 b$ & 7,76 & 8,41 & $8,09 b$ \\
\hline 5/8NE 3/8CH & 35,15 & 42,29 & $38,72 \mathrm{a}$ & 9,94 & 10,75 & $10,34 \mathrm{a}$ & 8,26 & 9,70 & $8,98 \mathrm{a}$ \\
\hline Média (Mean) & $34,60 \mathrm{~B}$ & $39,42 \mathrm{~A}$ & & $9,46 \mathrm{~B}$ & $10,31 \mathrm{~A}$ & & $8,01 \mathrm{~B}$ & $9,06 \mathrm{~A}$ & \\
\hline
\end{tabular}

a, b Médias seguidas por letras minúsculas diferentes na coluna, para a mesma característica, diferem $(P<0,05)$ pelo teste $F$.

A, B Médias seguidas por letras maiúsculas diferentes na linha, para a mesma característica, diferem $(P<0,05)$ pelo teste $F$.

a, b, c Médias seguidas por letras minúsculas diferentes, para a mesma característica, diferem $(P<0,05)$ pelo teste Tukey.

$a, b \quad$ Means followed by different small letters in the column, for the same characteristic, differ $(P<0.05)$ by $F$ test.

$A, B \quad$ Means followed by different capital letters in a row, for the same characteristic, differ $(P<0.05)$ by $F$ test.

$a, b, c \quad$ Means followed by different small letters, for the same characteristic, differ $(P<0.05)$ by Tukey test.

animais foram submetidos durante o período pré-experimental e experimental, pois os novilhos jovens sofreram restrição alimentar na fase pré-experimental, resultando em crescimento compensatório durante a fase de terminação (Pacheco et al., 2005a), enquanto os superjovens, em momento algum, foram submetidos a qualquer estresse nutricional, o que talvez tenha proporcionado maior desenvolvimento do couro.

As diferenças para peso de couro entre os grupos genéticos foram evidenciadas pela superioridade dos animais 5/8NE 3/8CH. Estudos relatam que animais taurinos apresentam maior peso de couro, graças à maior espessura de seu couro em relação ao dos zebuínos (Preston \& Willis, 1974; Berg \& Butterfield, 1976), o que não confere com os resultados deste estudo. Então, os maiores valores verificados para os animais com maior predominância de sangue zebuíno podem estar associados à maior área de superfície do couro, possivelmente em razão de a barbela e o cupim serem mais pronunciados. Além disso, conforme demonstrado por Pacheco et al. (2005b), animais 5/8NE 3/8CH apresentaram maiores valores para compri- 
mentos de carcaça, de perna e de braço, que são resultantes da maior adaptabilidade das raças zebuínas a climas mais quentes. Trabalhando com novilhos jovens 5/8NE 3/8CH, abatidos com diferentes pesos, Silva et al. (2003) relataram similaridade no peso de couro ajustado para peso de corpo vazio, com média de $10,04 \%$ quando o peso de abate passou de 425 para $510 \mathrm{~kg}$. Avaliando as características da carcaça de novilhos NE e cruzas F1 NE x Marchigiana e NE x Limousine, Galvão et al. (1991) verificaram maior peso de couro ajustado para peso de corpo vazio nos animais puros.

Para o frigorífico, o couro é um subproduto do abate de bovinos que gera importante fonte de receita. Além disso, é considerado um dos produtos com maior agregação de valor até chegar ao consumidor final, atuando em diversos setores da economia brasileira. Segundo ANUALPEC (2003), de 1998 a 2002, o kg de couro comercializado no atacado foi, em média, equivalente a $50,9 \%$ de cada $\mathrm{kg}$ de traseiro, $82,2 \%$ de cada $\mathrm{kg}$ de dianteiro e $89,2 \%$ de cada kg de costilhar ou ponta-de-agulha. Portanto, do ponto de vista comercial para o frigorífico e com base nos resultados obtidos neste estudo, seria mais vantajoso o abate de animais mais pesados e, conseqüentemente, com maior peso de couro, e não necessariamente com maior idade; e/ou o abate de genótipos com maior predominância de sangue zebuíno.

Para os demais componentes (Tabela 2), houve interação de categoria e grupo genético para pesos de orelha e cabeça quando expressos em relação ao peso de corpo vazio, de modo que novilhos 5/8NE 3/8CH da categoria jovem apresentaram maiores pesos. Interação significativa também foi verificada para pesos de patas e de cabeça quando ajustados para peso de abate. Para o componente patas, novilhos superjovens 5/8NE 3/8CH apresentaram maior peso que os 5/8CH 3/8NE da mesma categoria, com tendência numérica de superioridade para os animais 5/ 8NE 3/8CH em relação aos 5/8CH 3/8NE para todas as maneiras de expressão, o que está associado aos maiores comprimentos de perna e de braço, conforme apresentado por Pacheco et al. (2005b).

As médias referentes aos componentes do conjunto de órgãos vitais, expressos em diferentes formas de acordo com a categoria e o grupo genético, estão apresentados na Tabela 3.

Animais jovens apresentaram maior peso de coração, expresso em valores absolutos e ajustado para pesos de corpo vazio e de abate, que os superjovens, o que pode estar associado à maior taxa metabólica dos animais jovens, em razão da manifestação do ganho compensatório (Jones et al., 1985; Carstens et al., 1991; Hogg, 1991; Owens et al., 1995), relatado em maiores detalhes por Pacheco et al. (2005a). O peso de rins não foi influenciado pelos diferentes efeitos avaliados, enquanto o de pulmão, quando ajustado para peso de corpo vazio, foi maior nos animais jovens (1,50 vs 1,38\%).

Quanto ao fígado, maiores pesos foram verificados para os animais jovens e para os 5/8CH 3/8NE, em todas as maneiras de expressão deste componente. Segundo revisão de Cumby (2000), os órgãos vitais apresentam diferentes taxas metabólicas em comparação às das demais partes do corpo. O tamanho e a taxa metabólica dos órgãos sofrem modificações quando os animais são submetidos a dietas diferindo em qualidade e/ou quantidade, e estão diretamente relacionadas às exigências de energia para mantença dos animais. Quando em estresse nutricional, os primeiros tecidos a serem mobilizados são os de maior taxa metabólica, como o fígado e trato digestivo (Ryan et al., 1993), resultando em menores exigências de mantença. Este quadro se mantêm durante o período de realimentação, até o restabelecimento completo destes componentes, ocorrendo, então, aumento nas exigências de mantença dos animais. Cumby (2000) comenta, em sua revisão, que este período pode variar de dois a 90 dias.

Segundo Owens et al. (1993) e Ferrel \& Jenkins (1998), dos órgãos vitais, o fígado é o que apresenta as maiores taxas metabólicas, graças à sua importante participação no metabolismo dos nutrientes, estando diretamente relacionado ao consumo de alimentos. Com isso, para os animais 5/8CH 3/8NE deste estudo, seria esperado maior consumo de alimentos como possível explicação para o maior peso de fígado, conforme comentado anteriormente. No entanto, na avaliação do desempenho em confinamento dos animais deste estudo, Pacheco et al. (2005 a) verificaram similaridade nos consumos de matéria seca (kg/dia) e de energia líquida de mantença (Mcal/dia) entre os grupos genéticos avaliados. Em novilhos superjovens, Santos et al. (2003 b) observaram que os componentes do conjunto dos órgãos vitais (pulmão, fígado, rins, baço e coração) apresentaram similaridade entre animais $\mathrm{CH}$ e 3/4CH 1/4NE, tanto em valores absolutos como ajustados para peso de corpo vazio. Arboitte 
Tabela 3 - Médias para peso absoluto, em relação aos pesos de corpo vazio (PCV) e de abate (PAB) dos diferentes órgãos vitais

Table 3 - Means for absolute weights, in relation to empty body weight (PCV) and slaughter weight (PAB) of different vital organs

\begin{tabular}{|c|c|c|c|c|c|c|c|c|c|}
\hline \multirow[t]{2}{*}{$\begin{array}{l}\text { Grupo genético } \\
\text { Genetic group }\end{array}$} & \multicolumn{2}{|c|}{$\begin{array}{c}\text { Categoria } \\
\text { Category }\end{array}$} & \multirow[t]{2}{*}{$\begin{array}{l}\text { Média } \\
\text { Mean }\end{array}$} & \multicolumn{2}{|c|}{$\begin{array}{l}\text { Categoria } \\
\text { Category }\end{array}$} & \multirow[t]{2}{*}{$\begin{array}{l}\text { Média } \\
\text { Mean }\end{array}$} & \multicolumn{2}{|c|}{$\begin{array}{c}\text { Categoria } \\
\text { Category }\end{array}$} & \multirow[t]{2}{*}{$\begin{array}{l}\text { Média } \\
\text { Mean }\end{array}$} \\
\hline & $\begin{array}{l}\text { Jovem } \\
\text { Steer }\end{array}$ & $\begin{array}{l}\text { Superjovem } \\
\text { Young steer }\end{array}$ & & $\begin{array}{l}\text { Jovem } \\
\text { Steer }\end{array}$ & $\begin{array}{l}\text { Superjovem } \\
\text { Young steer }\end{array}$ & & $\begin{array}{l}\text { Jovem } \\
\text { Steer }\end{array}$ & $\begin{array}{l}\text { Superjovem } \\
\text { Young steer }\end{array}$ & \\
\hline & \multicolumn{2}{|c|}{ Coração (Heart), kg } & & \multicolumn{2}{|c|}{ Coração (Heart), \% PCV } & & \multicolumn{2}{|c|}{$\begin{array}{c}\text { Coração (Heart), } \\
\text { \% PAB }\end{array}$} & \\
\hline 5/8CH3/8NE & 1,69 & 1,42 & 1,56 & 0,45 & 0,38 & 0,42 & 0,39 & 0,33 & 0,36 \\
\hline 5/8NE3/8CH & 1,58 & 1,37 & 1,47 & 0,45 & 0,35 & 0,40 & 0,37 & 0,31 & 0,34 \\
\hline \multirow[t]{2}{*}{ Média (Mean) } & $1,63 \mathrm{~A}$ & $1,39 \mathrm{~B}$ & & $0,45 \mathrm{~A}$ & $0,36 \mathrm{~B}$ & & $0,38 \mathrm{~A}$ & $0,32 \mathrm{~B}$ & \\
\hline & \multicolumn{2}{|c|}{ Rins (Kidney), kg } & & \multicolumn{2}{|c|}{ Rins (Kidney), \% PCV } & & \multicolumn{2}{|c|}{ Rins (Kidney), \% РАB } & \\
\hline 5/8CH3/8NE & 0,89 & 0,80 & 0,84 & 0,23 & 0,22 & 0,22 & 0,20 & 0,18 & 0,19 \\
\hline 5/8NE 3/8CH & 0,75 & 0,85 & 0,80 & 0,21 & 0,22 & 0,22 & 0,18 & 0,20 & 0,19 \\
\hline \multirow[t]{2}{*}{ Média (Mean) } & 0,82 & 0,83 & & 0,22 & 0,22 & & 0,19 & 0,19 & \\
\hline & \multicolumn{2}{|c|}{ Pulmão (Lung), kg } & & \multicolumn{2}{|c|}{ Pulmão(Lung), \% PCV } & & \multicolumn{2}{|c|}{ Pulmão (Lung), \% PAB } & \\
\hline 5/8CH3/8NE & 5,63 & 5,30 & 5,43 & 1,50 & 1,41 & 1,45 & 1,29 & 1,20 & 1,25 \\
\hline 5/8NE 3/8CH & 5,22 & 5,27 & 5,29 & 1,49 & 1,34 & 1,42 & 1,24 & 1,21 & 1,23 \\
\hline \multirow[t]{2}{*}{ Média (Mean) } & 5,47 & 5,25 & & $1,50 \mathrm{~A}$ & $1,38 \mathrm{~B}$ & & 1,27 & 1,21 & \\
\hline & \multicolumn{2}{|c|}{ Fígado (Liver), kg } & & \multicolumn{2}{|c|}{ Fígado(Liver), \% PCV } & & \multicolumn{2}{|c|}{ Fígado (Liver), \% PAB } & \\
\hline 5/8CH3/8NE & 5,37 & 4,94 & $5,16 \mathrm{a}$ & 1,43 & 1,34 & $1,38 \mathrm{a}$ & 1,23 & 1,14 & $1,19 \mathrm{a}$ \\
\hline 5/8NE 3/8CH & 4,88 & 4,49 & $4,68 b$ & 1,39 & 1,14 & $1,27 \mathrm{~b}$ & 1,16 & 1,03 & $1,09 b$ \\
\hline \multirow[t]{2}{*}{ Média (Mean) } & $5,12 \mathrm{~A}$ & $4,72 \mathrm{~B}$ & & $1,41 \mathrm{~A}$ & $1,24 \mathrm{~B}$ & & $1,19 \mathrm{~A}$ & $1,09 \mathrm{~B}$ & \\
\hline & \multicolumn{2}{|c|}{ Baço (Spleen), kg } & & \multicolumn{2}{|c|}{ Baço (Spleen), \% PCV } & & \multicolumn{2}{|c|}{$\overline{\text { Baço (Spleen), \% PAB }}$} & \\
\hline 5/8CH3/8NE & 2,32 & 1,62 & 1,97 & $0,62 \mathrm{a}$ & $0,44 \mathrm{~b}$ & 0,53 & $0,53 \mathrm{a}$ & $0,37 \mathrm{~b}$ & 0,45 \\
\hline $5 / 8 \mathrm{NE} 3 / 8 \mathrm{CH}$ & 1,40 & 1,53 & 1,47 & $0,40 \mathrm{~b}$ & $0,39 b$ & 0,40 & $0,34 \mathrm{~b}$ & $0,36 \mathrm{~b}$ & 0,35 \\
\hline Média (Mean) & 1,86 & 1,58 & & 0,51 & 0,41 & & 0,43 & 0,36 & \\
\hline
\end{tabular}

a, b Médias seguidas por letras minúsculas diferentes na coluna, para a mesma característica, diferem $(P<0,05)$ pelo teste $F$.

A, B Médias seguidas por letras maiúsculas diferentes na linha, para a mesma característica, diferem $(P<0,05)$ pelo teste $F$.

a, b, c Médias seguidas por letras minúsculas diferentes, para a mesma característica, diferem $(P<0,05)$ pelo teste Tukey.

$a, b \quad$ Means followed by different small letters in the column, for the same characteristic, differ $(P<0.05)$ by $F$ test.

$A, B \quad$ Means followed by different capital letters in a row, for the same characteristic, differ $(P<0.05)$ by $F$ test.

$a, b, c \quad$ Means followed by different small letters, for the same characteristic, differ $(P<0.05)$ by Tukey test.

et al. (2003a), trabalhando com novilhos jovens 5/8NE 3/8CH abatidos com diferentes pesos, relataram aumento no peso de fígado e pulmão (ajustados para peso de corpo vazio) com o aumento no peso de abate (425 para $510 \mathrm{~kg})$.

Analisando o desempenho dos mesmos animais do presente estudo (Pacheco et al., 2005a), observou-se que novilhos jovens apresentaram ganho compensatório e maior exigência de energia líquida de mantença (Mcal/dia), o que permite afirmar que o período de terminação destes animais, que variou de 30 a 39 dias, foi suficiente para que o peso de fígado fosse restabelecido e incrementado para suportar a maior atividade metabólica resultante da maior ingestão de alimentos (Pacheco et al., 2005a). De acordo com a análise de correlação, o coeficiente verificado entre exigência de energia líquida de mantença com peso de fígado foi de 0,57 ( $\mathrm{P}=0,0035)$, com peso de coração, de 0,73 $(\mathrm{P}=0,0001)$, com peso de pulmão, de 0,40 $(\mathrm{P}=0,0502)$, com peso de rins de $0,14(\mathrm{P}=0,5246)$ e com peso de baço de $0,28(\mathrm{P}=0,1864)$.

Na Tabela 4 encontram-se os valores médios, em relação aos pesos absoluto e relativo e aos pesos de corpo vazio e de abate, dos diferentes tipos de gorduras internas, de acordo com a categoria e o grupo genético dos novilhos.

De maneira geral, os pesos de todos os componentes foram maiores para os animais superjovens, ressaltando-se que os animais desta categoria também apresentaram maior estado corporal ao abate (Pacheco et al., 2005a), carcaças com maior espessura de gordura subcutânea e quantidades total e percentual 
Tabela 4 - Médias para peso absoluto, em relação ao peso de corpo vazio (PCV) e peso de abate (PAB) dos diferentes tipos de gordura

Table 4 - Means for absolute weights, in relation to empty body weight (EBW) and slaughter weight (SW) of different types of fat

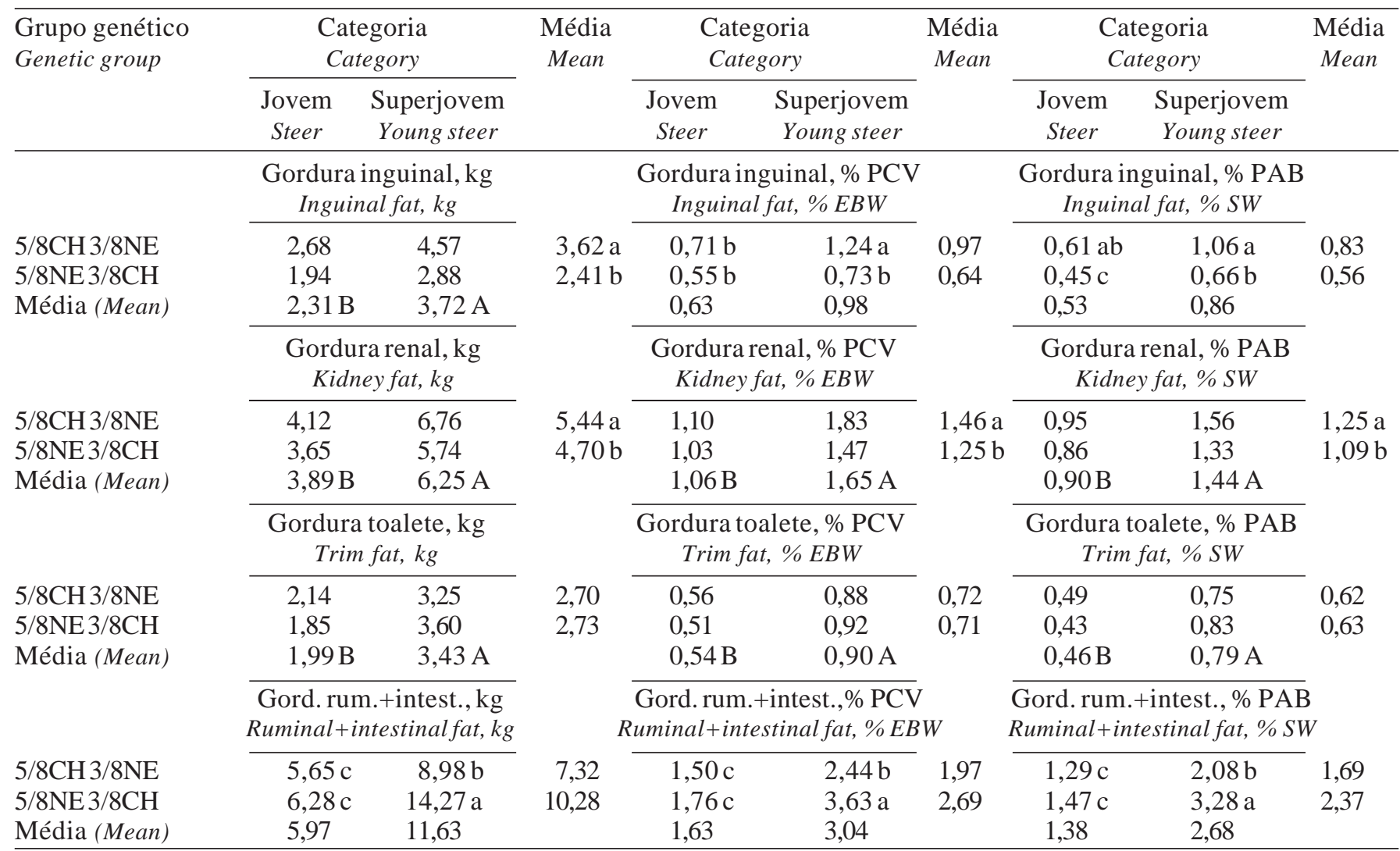

a, b Médias seguidas por letras minúsculas diferentes na coluna, para a mesma característica, diferem $(P<0,05)$ pelo teste $F$.

A, B Médias seguidas por letras maiúsculas diferentes na linha, para a mesma característica, diferem $(P<0,05)$ pelo teste $F$.

a, b, c Médias seguidas por letras minúsculas diferentes, para a mesma característica, diferem $(P<0,05)$ pelo teste Tukey.

$a, b \quad$ Means followed by different small letters in the column, for the same characteristic, differ $(P<0.05)$ by $F$ test.

$A, B \quad$ Means followed by different capital letters in a row, for the same characteristic, differ $(P<0.05)$ by $F$ test.

$a, b, c \quad$ Means followed by different small letters, for the same characteristic, differ $(P<0.05)$ by Tukey test.

de gordura, além de carne com maior grau de marmoreio, em relação aos novilhos jovens (Pacheco et al., 2005b; Pacheco et al., 2005c), como resultado da alteração na composição do ganho ao longo do período de alimentação.

Maior acúmulo de gordura foi verificado no rúmen+intestinos, que apresentou interação significativa de categoria e grupo genético e foi superior nos novilhos superjovens 5/8NE 3/8CH. Interação significativa também foi verificada para peso de gordura inguinal, quando expressa em porcentagem de corpo vazio, e peso de abate, com maiores valores verificados nos animais superjovens 5/8CH 3/8NE.

Novilhos 5/8CH 3/8NE apresentaram também inclusive maior acúmulo de gordura renal, expressa nas diferentes formas, que os 5/8NE 3/8CH. Para a gordura de toalete (recorte), em que são retirados os excessos de gordura localizados em vários pontos das extre- midades da carcaça, não houve diferença entre os grupos genéticos, em razão da similaridade no grau de acabamento de suas carcaças (Pacheco et al., 2005b).

Segundo Di Marco (1998), a gordura visceral acumulada é um desperdício que não agrega nenhum peso à carcaça, porém, afeta a eficiência do animal em converter alimento, sendo inevitável o seu acúmulo quando o animal avança no grau de terminação. Conforme apresentado por Pacheco et al. (2005a), numericamente, animais 5/8NE 3/8CH foram $6,8 \%$ menos eficientes em converter matéria seca consumida em ganho de peso e $6,9 \%$ menos eficientes em converter energia consumida em ganho de peso que os 5/8CH 3/8NE.

Na Tabela 5 foi determinado, por meio de análise de regressão, o grau de acúmulo de várias características relacionadas a gorduras, frente à primeira gordura corporal a ser acumulada na carcaça (intermuscular), 


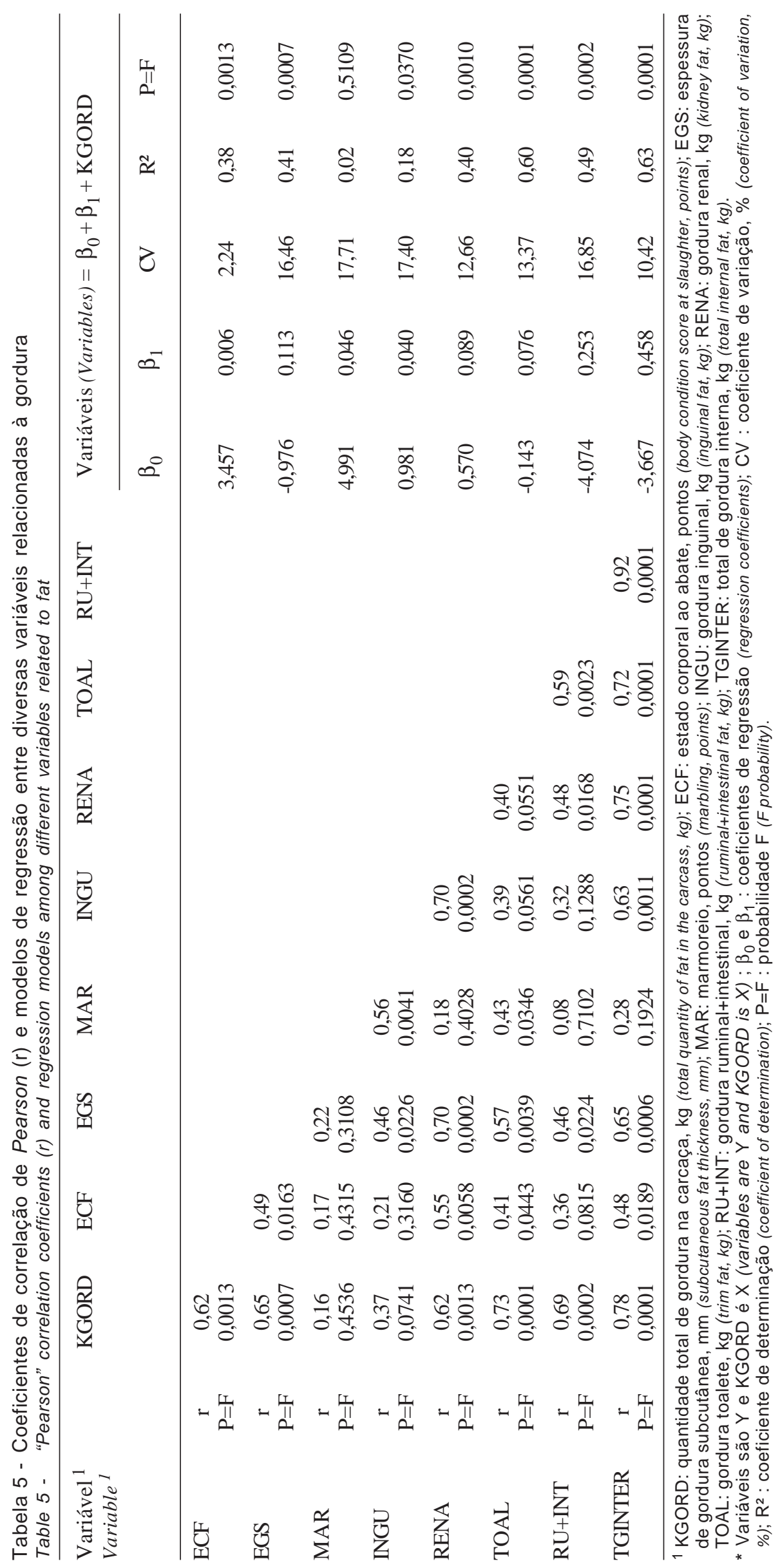

R. Bras. Zootec., v.34, n.5, p.1678-1690, 2005 
Tabela 6 - Médias para peso absoluto, em relação aos pesos de corpo vazio (PCV) e de abate (PAB), dos componentes vazios do trato digestivo

Table 6 - Means for absolute weights, in relation to empty body weight (EBW) and slaughter weight (SW), of empty components of digestive tract

\begin{tabular}{|c|c|c|c|c|c|c|c|c|c|}
\hline \multirow[t]{2}{*}{$\begin{array}{l}\text { Grupo genético } \\
\text { Genetic group }\end{array}$} & \multicolumn{2}{|c|}{$\begin{array}{l}\text { Categoria } \\
\text { Category }\end{array}$} & \multirow[t]{2}{*}{$\begin{array}{l}\text { Média } \\
\text { Mean }\end{array}$} & \multicolumn{2}{|c|}{$\begin{array}{l}\text { Categoria } \\
\text { Category }\end{array}$} & \multirow[t]{2}{*}{$\begin{array}{l}\text { Média } \\
\text { Mean }\end{array}$} & \multicolumn{2}{|c|}{$\begin{array}{l}\text { Categoria } \\
\text { Category }\end{array}$} & \multirow[t]{2}{*}{$\begin{array}{l}\text { Média } \\
\text { Mean }\end{array}$} \\
\hline & $\begin{array}{l}\text { Jovem } \\
\text { Steer }\end{array}$ & $\begin{array}{l}\text { Superjovem } \\
\text { Young steer }\end{array}$ & & $\begin{array}{l}\text { Jovem } \\
\text { Steer }\end{array}$ & $\begin{array}{l}\text { Superjovem } \\
\text { Young steer }\end{array}$ & & $\begin{array}{l}\text { Jovem } \\
\text { Steer }\end{array}$ & $\begin{array}{l}\text { Superjovem } \\
\text { Young steer }\end{array}$ & \\
\hline \multirow{5}{*}{$\begin{array}{l}\text { 5/8CH 3/8NE } \\
\text { 5/8NE 3/8CH } \\
\text { Média (Mean) }\end{array}$} & \multicolumn{2}{|c|}{$\begin{array}{l}\text { Rúmen+retículo } \\
\text { vazios, kg } \\
\text { Empty rumen+ } \\
\text { reticulum, kg }\end{array}$} & \multirow{5}{*}{$\begin{array}{l}8,42 \\
8,76\end{array}$} & \multicolumn{2}{|c|}{$\begin{array}{l}\text { Rúmen+retículo } \\
\text { vazios, \% PCV } \\
\text { Empty rumen+ } \\
\text { reticulum, \% EBW }\end{array}$} & \multirow{4}{*}{$\begin{array}{l}2,25 \\
2,36\end{array}$} & \multicolumn{2}{|c|}{$\begin{array}{l}\text { Rúmen+retículo } \\
\text { vazios, \%PAB } \\
\text { Empty rumen+ } \\
\text { reticulum, \% SW }\end{array}$} & \multirow{4}{*}{$\begin{array}{l}1,93 \\
2,04\end{array}$} \\
\hline & 8,95 & 7,88 & & 2,37 & 2,13 & & 2,05 & 1,82 & \\
\hline & 9,27 & 8,25 & & 2,62 & 2,10 & & 2,18 & 1,89 & \\
\hline & 9,11 & 8,07 & & $2,50 \mathrm{~A}$ & $2,11 \mathrm{~B}$ & & $2,11 \mathrm{~A}$ & $1,85 \mathrm{~B}$ & \\
\hline & \multicolumn{2}{|c|}{$\begin{array}{l}\text { Omaso vazio, } \mathrm{kg} \\
\text { Empty omasum, } \mathrm{kg}\end{array}$} & & \multicolumn{2}{|c|}{$\begin{array}{l}\text { Omaso vazio, \% PCV } \\
\text { Empty omasum, \% EBW }\end{array}$} & & \multicolumn{2}{|c|}{$\begin{array}{l}\text { Omaso vazio, \% PAB } \\
\text { Empty omasum, \% SW }\end{array}$} & \\
\hline Média (Mean) & \multicolumn{2}{|c|}{$\begin{array}{l}\text { Abomaso vazio, } \mathrm{kg} \\
\text { Empty abomasum, } \mathrm{kg}\end{array}$} & & \multicolumn{2}{|c|}{$\begin{array}{l}\text { Abomaso vazio, \% PCV } \\
\text { Empty abomasum, \% EBW }\end{array}$} & & \multicolumn{2}{|c|}{$\begin{array}{l}\text { Abomaso vazio, \% PAB } \\
\text { Empty abomasum, \% SW } \\
\end{array}$} & \\
\hline 5/8CH3/8NE & $2,80 \mathrm{a}$ & $1,90 \mathrm{~b}$ & 2,35 & $0,74 \mathrm{a}$ & $0,52 b$ & 0,63 & $0,64 \mathrm{a}$ & $0,44 b$ & 0,54 \\
\hline 5/8NE3/8CH & $1,83 \mathrm{~b}$ & $3,32 \mathrm{a}$ & 2,58 & $0,54 b$ & 0,85 a & 0,69 & $0,45 b$ & $0,76 \mathrm{a}$ & 0,60 \\
\hline \multirow[t]{2}{*}{ Média (Mean) } & 2,32 & 2,61 & & 0,64 & 0,68 & & 0,53 & 0,60 & \\
\hline & \multicolumn{2}{|c|}{$\begin{array}{c}\text { Intestinos vazios, kg } \\
\text { Empty intestines, } \mathrm{kg} \\
\end{array}$} & & \multicolumn{2}{|c|}{$\begin{array}{c}\text { Intestinos vazios, \% PCV } \\
\text { Empty intestines, \% EBW } \\
\end{array}$} & & \multicolumn{2}{|c|}{$\begin{array}{c}\text { Intestinos vazios, \% PAB } \\
\text { Empty intestines, \% SW }\end{array}$} & \\
\hline 5/8CH3/8NE & $14,58 \mathrm{a}$ & $12,18 \mathrm{ab}$ & 13,38 & 3,88 & 3,29 & 3,58 & 3,34 & 2,80 & 3,07 \\
\hline $5 / 8 \mathrm{NE} 3 / 8 \mathrm{CH}$ & $11,45 b$ & $12,45 \mathrm{ab}$ & 11,95 & 3,27 & 3,17 & 3,22 & 2,72 & 2,86 & 2,79 \\
\hline
\end{tabular}

A, B Médias seguidas por letras maiúsculas diferentes na linha, para a mesma característica, diferem (P<0,05) pelo teste $F$.

a, b, c Médias seguidas por letras minúsculas diferentes, para a mesma característica, diferem $(P<0,05)$ pelo teste $T u k e y$.

$A, B \quad$ Means followed by different capital letters in a row, for the same characteristic, differ $(P<0.05)$ by $F$ test.

$a, b, c \quad$ Means followed by different small letters, for the same characteristic, differ $(P<0.05)$ by Tukey test.

segundo Berg \& Butterfield (1976). Para isto, foram utilizados resultados de algumas características avaliadas por Pacheco et al. (2005a) (estado corporal ao abate), Pacheco et al. (2005b) (espessura de gordura subcutânea) e Pacheco et al. (2005c) (quantidade total de gordura e marmoreio).

De acordo com os modelos de regressão (Tabela 5), cada kg de gordura intermuscular depositado na carcaça, denominado KGORD, representou incremento de 0,006 pontos no estado corporal ao abate e incremento de $0,113 \mathrm{~mm}$ na espessura de gordura subcutânea. Para o conjunto das gorduras internas, o aumento foi de 0,458 kg para cada KGORD acrescentado. Os componentes que integram o conjunto das gorduras internas, quando analisados separadamente, apresentaram diferentes comportamentos na velocidade de acúmulo de gordura nas diversas partes do corpo do animal, por KGORD, sendo mais expressivo o incremento da gordura ruminal+intestinal $(0,253 \mathrm{~kg})$, seguido pela gordura renal $(0,089 \mathrm{~kg})$, de toalete $(0,076 \mathrm{~kg})$ e, por último, pela inguinal $(0,040)$.

Verificou-se, ainda, que as características relacionadas à gordura (na carcaça, na carne e nos componentes do corpo vazio) correlacionam-se positivamente entre si. Contudo, para o marmoreio da carne, a relação não foi significativa com a quantidade total de gordura na carcaça e com a espessura de gordura subcutânea, demonstrando que a gordura intramuscular apresenta menor velocidade de crescimento e que seria necessário maior período de terminação, que resultaria em maior acúmulo de gordura corporal e subcutânea, para proporcionar maiores incrementos no marmoreio da carne. Segundo Di Marco (1998), a gordura se acumula nas diferentes partes do corpo do 
Tabela 7 - Médias para peso absoluto, em relação aos pesos de corpo vazio (PCV) e de abate (PAB) dos conjuntos dos componentes

Table 7 - Means for absolute weights, in relation to empty body weight (EBW) and slaughter weight (SW) of overall components

\begin{tabular}{|c|c|c|c|c|c|c|c|c|c|}
\hline \multirow[t]{2}{*}{$\begin{array}{l}\text { Grupo genético } \\
\text { Genetic group }\end{array}$} & \multicolumn{2}{|c|}{$\begin{array}{l}\text { Categoria } \\
\text { Category }\end{array}$} & \multirow[t]{2}{*}{$\begin{array}{l}\text { Média } \\
\text { Mean }\end{array}$} & \multicolumn{2}{|c|}{$\begin{array}{l}\text { Categoria } \\
\text { Category }\end{array}$} & \multirow[t]{2}{*}{$\begin{array}{l}\text { Média } \\
\text { Mean }\end{array}$} & \multicolumn{2}{|c|}{$\begin{array}{l}\text { Categoria } \\
\text { Category }\end{array}$} & \multirow[t]{2}{*}{$\begin{array}{l}\text { Média } \\
\text { Mean }\end{array}$} \\
\hline & $\begin{array}{l}\text { Jovem } \\
\text { Steer }\end{array}$ & $\begin{array}{l}\text { Superjovem } \\
\text { Young steer }\end{array}$ & & $\begin{array}{l}\text { Jovem } \\
\text { Steer }\end{array}$ & $\begin{array}{l}\text { Superjovem } \\
\text { Young steer }\end{array}$ & & $\begin{array}{l}\text { Jovem } \\
\text { Steer }\end{array}$ & $\begin{array}{l}\text { Superjovem } \\
\text { Young steer }\end{array}$ & \\
\hline & \multicolumn{2}{|c|}{$\begin{array}{c}\text { Total componentes } \\
\text { externos, kg } \\
\text { Total external } \\
\text { components, } \mathrm{kg} \\
\end{array}$} & & \multicolumn{2}{|c|}{$\begin{array}{c}\text { Total componentes } \\
\text { externos,\% PCV } \\
\text { Total external } \\
\text { components, \% EBW }\end{array}$} & & \multicolumn{2}{|c|}{$\begin{array}{c}\text { Total componentes } \\
\text { externos,\% PAB } \\
\text { Total external } \\
\text { components, \% SW }\end{array}$} & \\
\hline $\begin{array}{l}\text { 5/8CH3/8NE } \\
\text { 5/8NE 3/8CH } \\
\text { Média (Mean) }\end{array}$ & $\begin{array}{l}56,91 \\
58,23 \\
57,57\end{array}$ & $\begin{array}{l}58,65 \\
64,48 \\
61,56\end{array}$ & $\begin{array}{l}57,78 \\
61,36\end{array}$ & $\begin{array}{l}15,07 \\
16,46 \\
15,77\end{array}$ & $\begin{array}{l}15,85 \\
16,40 \\
16,12\end{array}$ & $\begin{array}{l}15,46 \mathrm{~b} \\
16,43 \mathrm{a}\end{array}$ & $\begin{array}{l}13,00 \\
13,69 \\
13,34 \mathrm{~B}\end{array}$ & $\begin{array}{l}13,51 \\
14,81 \\
14,16 \mathrm{~A}\end{array}$ & $\begin{array}{l}13,25 \mathrm{~b} \\
14,25 \mathrm{a}\end{array}$ \\
\hline Média (Mean) & \multicolumn{2}{|c|}{$\begin{array}{c}\text { Total órgãos vitais, kg } \\
\text { Total vital organs, } \mathrm{kg}\end{array}$} & & \multicolumn{2}{|c|}{$\begin{array}{c}\text { Total órgãos vitais, \% PCV } \\
\text { Total vital organs, \% EBW }\end{array}$} & & \multicolumn{2}{|c|}{$\begin{array}{c}\text { Total órgãos vitais, \% PAB } \\
\text { Total vital organs, \% SW }\end{array}$} & \\
\hline Média (Mean) & \multicolumn{2}{|c|}{$\begin{array}{c}\text { Total gordura } \\
\text { interna, kg } \\
\text { Total internal fat, } \mathrm{kg}\end{array}$} & & \multicolumn{2}{|c|}{$\begin{array}{c}\text { Total gordura } \\
\text { interna, \% PCV } \\
\text { Total internal fat, \% EBW }\end{array}$} & & \multicolumn{2}{|c|}{$\begin{array}{c}\text { Total gordura } \\
\text { interna, \%PAB } \\
\text { Total internal fat, \% SW }\end{array}$} & \\
\hline $\begin{array}{l}\text { 5/8CH3/8NE } \\
\text { 5/8NE 3/8CH } \\
\text { Média (Mean) }\end{array}$ & $\begin{array}{l}14,59 \\
13,72 \\
14,16 \mathrm{~B}\end{array}$ & $\begin{array}{l}23,57 \\
26,49 \\
25,03 \mathrm{~A}\end{array}$ & $\begin{array}{l}19,08 \\
20,11\end{array}$ & $\begin{array}{l}3,87 \\
3,84 \\
3,86 \mathrm{~B}\end{array}$ & $\begin{array}{l}6,39 \\
6,75 \\
6,57 \mathrm{~A}\end{array}$ & $\begin{array}{l}5,13 \\
5,30\end{array}$ & $\begin{array}{l}3,34 \\
3,21 \\
3,27 \mathrm{~B}\end{array}$ & $\begin{array}{l}5,45 \\
6,09 \\
5,77 \mathrm{~A}\end{array}$ & $\begin{array}{l}4,39 \\
4,65\end{array}$ \\
\hline
\end{tabular}

a, b Médias seguidas por letras minúsculas diferentes na coluna, para a mesma característica, diferem $(P<0,05)$ pelo teste $F$.

A, B Médias seguidas por letras maiúsculas diferentes na linha, para a mesma característica, diferem $(P<0,05)$ pelo teste $F$.

$a, b$ Means followed by different small letters in the column, for the same characteristic, differ $(P<0.05)$ by $F$ test.

$A, B$ Means followed by different capital letters in a row, for the same characteristic, differ $(P<0.05)$ by $F$ test.

animal segundo a seguinte ordem decrescente: intermuscular, subcutânea, interna, visceral e intramuscular, estando de acordo com os resultados obtidos neste estudo.

Na Tabela 6, encontram-se os valores médios referentes aos componentes vazios do trato digestivo, expressos em peso absoluto, em relação aos pesos de corpo vazio e de abate, de acordo com a categoria e o grupo genético.

Animais da categoria jovem apresentaram, significativamente, maiores pesos de rúmen+retículo e omaso vazios (tanto expressos por peso de corpo vazio como por peso de abate) que os superjovens. O tamanho do trato digestivo pode variar em função do tipo de dieta: volumosa ou concentrada (Jones et al., 1985; Owens et al., 1995; Gesualdi Jr. et al., 2001; Ribeiro et al., 2001; Véras et al., 2001), da quantidade de alimento consumido e do histórico nutricional dos animais. Hogg (1991) afirma que animais em ganho compensatório apresentam au- mento no consumo de alimentos, no conteúdo e tamanho do trato gastrintestinal, como ocorrido nos animais jovens neste estudo, que apresentaram manifestação de ganho compensatório, maior consumo de matéria seca (Pacheco et al., 2005a) e maior peso de alguns componentes constituintes do trato digestivo vazio.

Entre os grupos genéticos, não houve diferença para rúmen+retículo, intestinos e omaso quando ajustados para pesos de corpo vazio e de abate, apesar de os animais 5/8NE 3/8CH terem apresentado maior consumo diário de matéria seca em percentagem do peso vivo e por unidade de tamanho metabólico (Pacheco et al., 2005a). Santos et al. (2003 a) verificaram maiores pesos de intestinos vazios ajustados por peso de corpo vazio em animais $\mathrm{CH}$ que nos $3 / 4 \mathrm{CH}$ 1/4NE, havendo também tendência de superioridade para os pesos de rúmen+retículo e omaso vazios.

Houve interação significativa para as diferentes maneiras de se expressar o peso de abomaso vazio. 
Tabela 8 - Médias para peso absoluto, em relação aos pesos de corpo vazio (PCV) e de abate (PAB) dos conjuntos dos componentes

Table 8 - Means for absolute weights, in relation to empty body weight (EBW) and slaughter weight (SW) of overall components

\begin{tabular}{|c|c|c|c|c|c|c|c|c|c|}
\hline \multirow[t]{2}{*}{$\begin{array}{l}\text { Grupo genético } \\
\text { Genetic group }\end{array}$} & \multicolumn{2}{|c|}{$\begin{array}{c}\text { Categoria } \\
\text { Category }\end{array}$} & \multirow[t]{2}{*}{$\begin{array}{l}\text { Média } \\
\text { Mean }\end{array}$} & \multicolumn{2}{|c|}{$\begin{array}{c}\text { Categoria } \\
\text { Category }\end{array}$} & \multirow[t]{2}{*}{$\begin{array}{l}\text { Média } \\
\text { Mean }\end{array}$} & \multicolumn{2}{|c|}{$\begin{array}{c}\text { Categoria } \\
\text { Category }\end{array}$} & \multirow[t]{2}{*}{$\begin{array}{l}\text { Média } \\
\text { Mean }\end{array}$} \\
\hline & $\begin{array}{l}\text { Jovem } \\
\text { Steer }\end{array}$ & $\begin{array}{l}\text { Superjovem } \\
\text { Young steer }\end{array}$ & & $\begin{array}{l}\text { Jovem } \\
\text { Steer }\end{array}$ & $\begin{array}{l}\text { Superjovem } \\
\text { Young steer }\end{array}$ & & $\begin{array}{l}\text { Jovem } \\
\text { Steer }\end{array}$ & $\begin{array}{c}\text { Superjovem } \\
\text { Young steer }\end{array}$ & \\
\hline & \multicolumn{2}{|c|}{$\begin{array}{c}\text { Total trato digestivo } \\
\text { vazio, } \mathrm{kg} \\
\text { Total empty digestive } \\
\text { tract, } \mathrm{kg}\end{array}$} & & \multicolumn{2}{|c|}{$\begin{array}{c}\text { Total trato digestivo } \\
\text { vazio, \% PCV } \\
\text { Total empty digestive } \\
\text { tract, \% EBW }\end{array}$} & \multirow{3}{*}{$\begin{array}{l}7,53 \mathrm{a} \\
6,95 \mathrm{~b}\end{array}$} & \multicolumn{2}{|c|}{$\begin{array}{c}\text { Total trato digestivo } \\
\text { vazio, \% PAB } \\
\text { Total empty digestive } \\
\text { tract, \% SW }\end{array}$} & \\
\hline $\begin{array}{l}\text { 5/8CH3/8NE } \\
\text { 5/8NE 3/8CH } \\
\text { Média (Mean) }\end{array}$ & $\begin{array}{l}30,62 \\
25,68 \\
28,15\end{array}$ & $\begin{array}{l}25,63 \\
25,93 \\
25,78\end{array}$ & $\begin{array}{l}28,13 \\
25,81\end{array}$ & $\begin{array}{l}8,13 \\
7,29 \\
7,71 \mathrm{~A}\end{array}$ & $\begin{array}{l}6,94 \\
6,60 \\
6,77 \mathrm{~B}\end{array}$ & & $\begin{array}{l}7,01 \mathrm{a} \\
6,06 \mathrm{~b} \\
6,53\end{array}$ & $\begin{array}{l}5,91 \mathrm{~b} \\
5,96 \mathrm{~b} \\
5,94\end{array}$ & $\begin{array}{l}6,46 \\
6,01\end{array}$ \\
\hline Média (Mean) & \multicolumn{2}{|c|}{$\begin{array}{l}\text { Sangue, kg } \\
\text { Blood, kg }\end{array}$} & & \multicolumn{2}{|c|}{$\begin{array}{c}\text { Sangue, \% PCV } \\
\text { Blood, \% EBW }\end{array}$} & & \multicolumn{2}{|c|}{$\begin{array}{c}\text { Sangue, \% PAB } \\
\text { Blood, \% SW }\end{array}$} & \\
\hline
\end{tabular}

a, b Médias seguidas por letras minúsculas diferentes na coluna, para a mesma característica, diferem ( $<<0,05)$ pelo teste $F$.

A, B Médias seguidas por letras maiúsculas diferentes na linha, para a mesma característica, diferem ( $P<0,05)$ pelo teste $F$.

$\mathrm{a}, \mathrm{b}, \mathrm{c}$ Médias seguidas por letras minúsculas diferentes, para a mesma característica, diferem $(\mathrm{P}<0,05)$ pelo teste Tukey.

$a, b \quad$ Means followed by different small letters in the column, for the same characteristic, differ $(P<0.05)$ by $F$ test.

$A, B \quad$ Means followed by different capital letters in a row, for the same characteristic, differ $(P<0.05)$ by $F$ test.

$a, b, c \quad$ Means followed by different small letters, for the same characteristic, differ $(P<0.05)$ by Tukey test.

Novilhos 5/8CH 3/8NE apresentaram maior peso quando jovens e menor quando superjovens. Possível explicação estaria associada à seleção dos componentes da dieta (volumoso e concentrado) pelos animais, mesmo contendo a mesma relação volumoso:concentrado. Menezes et al. (2005), trabalhando com novilhos de gerações avançadas do cruzamento alternado entre as raças Charolês e Nelore terminados em confinamento, recebendo dieta com relação volumoso:concentrado de 52:48, verificaram que novilhos com predominância Charolês foram mais seletivos no consumo dos alimentos, resultando em maior consumo de energia em relação aos novilhos com predominância de Nelore no genótipo.

Nas Tabelas 7 e 8, encontram-se as médias referentes aos componentes do corpo vazio agrupados em conjuntos, expressos em peso absoluto, e corrigidos para pesos de corpo vazio e de abate.

Animais da categoria jovem apresentaram maior peso total de órgãos vitais (expresso nas diferentes formas) que os superjovens. Segundo a análise de correlação, esta característica é correlacionada significativamente e em ordem decrescente, com os pesos de fígado ( $\mathrm{r}=0,84 ; \mathrm{P}=0,0001)$, pulmão ( $\mathrm{r}=0,73$; $\mathrm{P}=0,0001)$, coração $(\mathrm{r}=0,73 ; \mathrm{P}=0,0001)$ e baço ( $r=0,56 ; P=0,0045)$. Vaz et al. (2001), ao avaliarem os componentes do corpo vazio de machos e fêmeas Braford superjovens relataram maior peso total de órgãos internos para as fêmeas (4,17 vs 3,97\%), quando ajustado para peso de carcaça quente.

Superioridade em favor dos novilhos jovens foi verificada para o conjunto trato digestivo vazio, quando ajustado para peso de corpo vazio ( 7,71 vs $6,77 \%$ ), que esteve associado significativamente com o peso vazio dos intestinos ( $\mathrm{r}=0,80 ; \mathrm{P}=0,0001)$, seguido pelo peso vazio do rúmen+retículo $(\mathrm{r}=0,54 ; \mathrm{P}=0,0001)$ e omaso ( $r=0,52 ; \mathrm{P}=0,0888)$.

Houve superioridade dos novilhos superjovens, nas diferentes maneiras de expressão, para o total de gorduras internas, o que era esperado, uma vez que todas as variáveis que compõem esta características apresentaram maiores valores em relação aos novilhos jovens (Tabela 4). Arboitte et al. (2003b), ao avaliarem os componentes do corpo vazio de novilhos jovens $5 / 8 \mathrm{NE} 3 / 8 \mathrm{CH}$, verificaram que o peso de gorduras internas (toalete, renal, inguinal e ruminal), expresso em valores absolutos e por peso de corpo vazio, elevou com o incremento no peso de abate dos animais, acompanhando o aumento na deposição de gordura na carcaça (Arboitte et al., 2004).

Entre os grupos genéticos, os novilhos 5/8CH 3/8NE apresentaram maiores pesos para os totais de órgãos 
vitais e trato digestivo vazio, este último quando ajustado para peso de corpo vazio. Comportamento contrário foi observado para o peso total de componentes externos, que foi superior para os 5/8NE 3/8CH, e apresentou relação positiva com peso de couro $(\mathrm{r}=0,96$; $\mathrm{P}=0,0001)$, patas $(\mathrm{r}=0,75 ; \mathrm{P}=0,0001)$ e cabeça $(r=0,43 ; P=0,0378)$. Em revisão, Véras et al. (2001) constataram que animais taurinos e/ou mestiços, especialmente os de origem leiteira, apresentam maior massa de órgãos vitais que os zebuínos. Avaliando os componentes do corpo vazio de novilhos superjovens, Santos et al. (2003 a, b) relataram maior peso do trato gastrintestinal vazio, ajustado para peso de corpo vazio, em animais $\mathrm{CH}$, em relação aos 3/4CH 1/4NE, e similaridade para peso dos órgãos vitais (pulmão, coração, fígado, rins, baço). Em novilhos jovens 5/8NE 3/8CH, abatidos com 425, 467 e $510 \mathrm{~kg}$, Arboitte et al. (2003 a) e Silva et al. (2003) verificaram similaridade para peso total de componentes externos (média de 15,86\%) e decréscimo no peso total de órgãos internos com o aumento no peso de abate dos animais, sendo ambas características ajustadas para peso de corpo vazio.

Para o componente sangue, houve diferença apenas entre os grupos genéticos. Novilhos com maior predominância de sangue Charolês apresentaram maior peso que aqueles com maior predominância de sangue Nelore (Tabela 8) no genótipo. Este resultado pode ser explicado pela positiva relação com o peso dos órgãos vitais $(r=0,19)$ e do trato digestivo vazio $(r=0,21)$, provavelmente para suportar a maior taxa metabólica nestes animais. Estudando o tamanho de órgãos e vísceras de bezerros holandeses alimentados com diferentes níveis de concentrado, Ribeiro et al. (2001) relataram que o peso de sangue foi proporcional ao tamanho relativo dos órgãos.

\section{Conclusões}

A deposição de gorduras internas foi mais evidente nos animais superjovens, enquanto a maior proporção de sangue Nelore no genótipo resultou em maior peso de couro.

\section{Literatura Citada}

ANUALPEC - Anuário da Pecuária Brasileira. São Paulo: OESP Gráfica, 2003. 400p.

ARBOITTE, M.Z.; BERNARDES, R.A.C.; RESTLE, J. et al. Características das partes do corpo não integrantes da carcaça e desenvolvimento do trato gastrintestinal de novilhos 5/8Nelore 3/8Charolês abatidos em três estádios de desenvolvimento - 3. Gordura interna. In: REUNIÃO ANUAL DA SOCIEDADE BRASILEIRA DE ZOOTECNIA, 40., 2003, Santa Maria. Anais... Santa Maria: Sociedade Brasileira de Zootecnia, 2003b. CD-ROM.

ARBOITTE, M.Z.; BRONDANI, I.L.; RESTLE, J. et al. Características das partes do corpo não integrantes da carcaça e desenvolvimento do trato gastrintestinal de novilhos 5/8Nelore 3/8Charolês abatidos em três estádios de desenvolvimento 2. Órgãos vitais. In: REUNIÃO ANUAL DA SOCIEDADE BRASILEIRA DE ZOOTECNIA, 40., 2003, Santa Maria. Anais... Santa Maria: Sociedade Brasileira de Zootecnia, 2003a. CD-ROM.

ARBOITTE, M.Z.; RESTLE, J.; ALVES FILHO, D.C. et al. Composição física da carcaça, qualidade da carne e conteúdo de colesterol no músculo Longissimus dorsi de novilhos 5/8 Nelore-3/8 Charolês terminados em confinamento e abatidos em diferentes estádios de maturidade. Revista Brasileira de Zootecnia, v.33, n.4, p.959-968, 2004.

BERG, R.T.; BUTTERFIELD, R.M. New concepts of cattle growth. Sydney: Sydney University Press, 1976. 240p.

CARSTENS, G.E.; JOHNSON, D.E.; ELLENBERGER, M.A. et al. Physical and chemical components of the empty body during compensatory growth in beef steers. Journal of Animal Science, v.69, p.3251-3264, 1991.

CUMBY, J. Visceral organ development during restriction and re-alimentation. In: CANT, J. (Ed.) Proceedings of the 2000 course in ruminant digestion and metabolism - ANSC 6260. University of Guelph, 2000. p.23-29.

DI MARCO, O.N. Crecimiento de vacunos para carne. 1.ed. Mar del Plata: Balcarce, 1998. 246p.

FERREIRA, M.A.; VALADARES FILHO, S.C.; MUNIZ, E.B. et al. Características das carcaças, biometria do trato gastrintestinal, tamanho dos órgãos internos e conteúdo gastrintestinal de bovinos F1 Simental x Nelore alimentados com dietas contendo vários níveis de concentrado. Revista Brasileira de Zootecnia, v.29, n.4, p.1174-1182, 2000.

FERREL, C.L.; JENKINS, T.G. Body composition and energy utilization by steers of diverse genotypes fed a high-concentrate diet during the finishing period: I: Angus, Belgian Blue, Hereford, and Piedmontese sires. Journal of Animal Science, v.76, p.637-646, 1998.

GALVÃO, J.G.; FONTES, C.A.A.; PIRES, C.C. et al. Características e composição física da carcaça de bovinos não-castrados, abatidos em três estágios de maturidade (estudo II) de três grupos raciais. Revista da Sociedade Brasileira de Zootecnia, v.20, n.5, p.502-512, 1991.

GESUALDI JR., A.; VELOSO, C.M.; PAULINO, M.F. et al. Níveis de concentrado na dieta de bovinos F1 Limousin $\mathrm{x}$ Nelore: Peso dos órgãos internos e trato digestivo. Revista Brasileira de Zootecnia, v.30, n.6, p.1866-1871, 2001. HOGG, B.W. Compensatory growth in ruminants. In: PEARSON, A.M.; DUTSON, T.R. (Eds.) Growth regulation in farm animal: advances in meat research. Corvallis Oregon: Elsevier, 1991. v.7, p.103-134.

JONES, S.D.M.; ROMPALA, R.E.; JEREMIAH, L.E. Growth and composition of the empty body in steers of different maturity types fed concentrate or forage diets. Journal of Animal Science, v.60, n.2, p.427-433, 1985. 
MENEZES, L.F.G.; RESTLE, J.; ALVES FILHO, D.C. et al. Desempenho de novilhos de gerações avançadas do cruzamento alternado entre as raças Charolês e Nelore, terminados em confinamento. Revista Brasileira de Zootecnia, NO PRELO, 2005.

MORENO, J.A. Clima do Rio Grande do Sul. Porto Alegre: Secretaria da Agricultura, 1961. 41p.

NATIONAL RESEARCH COUNCIL - NRC. Nutrient requirements of domestic animals. 7.ed. Washington, D.C.: National Academy Press, 1996. 242p.

OWENS, F.N.; DONALD, R.G.; SECRIST, D.S. et al. Review of some aspects of growth and development of feedlot cattle. Journal of Animal Science, v.73, p.3152-3172, 1995.

OWENS, F.N.; DUBESKI, P.; HANSON, C.F. Factors that alter the growth and development of ruminants. Journal of Animal Science, v.71, p.3138-3150, 1993.

PACHECO, P.S.; RESTLE, J.; SILVA, J.H.S. et al. Desempenho de novilhos jovens e superjovens de diferentes grupos genéticos terminados em confinamento. Revista Brasileira de Zootecnia, v.34, n.3, p.963-975, 2005a.

PACHECO, P.S.; SILVA, J.H.S.; RESTLE, J. et al. Características quantitativas da carcaça de novilhos jovens e superjovens de diferentes grupos genéticos. Revista Brasileira de Zootecnia, v.34, n.5, p.1666-1677, 2005b.

PACHECO, P.S.; RESTLE, J.; SILVA, J.H.S. et al. Composição física da carcaça e qualidade da carne de novilhos jovens e superjovens de diferentes grupos genéticos. Revista Brasileira de Zootecnia, v.34, n.5, p.1691-1703, 2005c.

PRESTON, T.R.; WILLIS, M.B. Intensive beef cattle production. 2.ed. Oxford: Pergamon Press, 1974. 546p.

RESTLE, J.; BRONDANI, I.L.; CERDÓTES, L. et al. Peso das vísceras e o rendimento de carcaça de bovinos Braford superprecoces, terminados em pastagem cultivada sob pastejo horário, com suplementação de grão de sorgo ou de aveia. In: REUNIÃO ANUAL DA SOCIEDADE BRASILEIRA DE ZOOTECNIA, 38., 2001, Piracicaba. Anais... Piracicaba: Sociedade Brasileira de Zooctenia, 2001, CD-ROM, cód 6-1079.

RIBEIRO, T.R.; PEREIRA, J.C.; LEÃO, M.I. et al. Tamanho de órgãos e vísceras de bezerros Holandeses, para produção de vitelos, recebendo dietas com diferentes níveis de concentrado. Revista Brasileira de Zootecnia, v.30, n.6, p.2163-2168, 2001 (suplemento).

RYAN, W.J.; WILLIAMS, I.H.; MOIR, R.J. Compensatory growth in sheep and cattle. II. Changes in body composition and tissues weights. Australian Journal of Agricultural Research, v.44, p.1623-1633, 1993.
SANTOS, A.P.; BRONDANI, I.L.; RESTLE, J. et al. Influência do grupo genético e da dieta alimentar no peso do corpo vazio e órgãos vitais de novilhos superprecoce. In: REUNIÃO ANUAL DA SOCIEDADE BRASILEIRA DE ZOOTECNIA, 40., 2003, Santa Maria. Anais... Santa Maria: Sociedade Brasileira de Zootecnia, 2003b. CD-ROM.

SANTOS, A.P.; RESTLE, J.; PASCOAL, L.L. et al. Influência do grupo genético e da dieta alimentar no peso do corpo vazio e trato gastrintestinal de novilhos superprecoce. In: REUNIÃO ANUAL DA SOCIEDADE BRASILEIRA DE ZOOTECNIA, 40., 2003, Santa Maria. Anais... Santa Maria: Sociedade Brasileira de Zootecnia, 2003a. CD-ROM.

STATISTICAL ANALYSIS SYSTEMS - SAS. User's guide. Version 6, Cary: v.2, 1997. 1052p.

SILVA, J.H.S.; PASCOAL, L.L.; RESTLE, J. et al. Características das partes do corpo não integrantes da carcaça e desenvolvimento do trato gastrintestinal de novilhos 5/8Nelore 3/8Charolês abatidos em três estádios de desenvolvimento - 1 . Órgãos externos. In: REUNIÃO ANUAL DA SOCIEDADE BRASILEIRA DE ZOOTECNIA, 40., 2003, Santa Maria. Anais... Santa Maria: Sociedade Brasileira de Zootecnia, 2003, CD-ROM.

VAZ, F.N.; RESTLE, J.; ALVES FILHO, D.C. et al. Peso das vísceras e rendimento de carcaça de novilhos ou novilhas Braford superprecoces, terminados com suplementação em pastagem cultivada sob pastejo controlado. In: REUNIÃO ANUAL DA SOCIEDADE BRASILEIRA DE ZOOTECNIA, 38., 2001, Piracicaba. Anais... Piracicaba: Sociedade Brasileira de Zootecnia, 2001, CD-ROM, cód 8-1078.

VÉRAS, A.S.C.; VALADARES FILHO, S.C.; SILVA, J.F.C. et al. Efeito do nível de concentrado sobre o peso dos órgãos internos e do conteúdo gastrintestinal de bovinos Nelore não-castrados. Revista Brasileira de Zootecnia, v.30, n.3, p.1120-1126, 2001 (suplemento 1).

Recebido em: 06/04/04 Aceito em: 29/04/05 